\title{
Extracellular a-synuclein levels are regulated by neuronal activity
}

\author{
Kaoru Yamada* (10) and Takeshi Iwatsubo*
}

\begin{abstract}
Background: a-Synuclein is a presynaptic protein abundant in the cytoplasmic compartment of neurons, whereas its presence in the extracellular space has also been observed under physiological conditions. Extracellular a-synuclein has pathological significance, exhibiting cellular toxicity and impairment of synaptic transmission. Notably, misfolded a-synuclein drives the cell-to-cell propagation of pathology via the extracellular space. However, the primary mechanism that regulates the extracellular levels of a-synuclein remains to be determined.

Methods: Using several mechanistically distinct methods to modulate neuronal/synaptic activities in primary neuronal culture and in vivo microdialysis, we examined the involvement of neuronal/synaptic activities on a-synuclein release.

Results: We demonstrate here that physiological release of endogenous a-synuclein highly depends on intrinsic neuronal activities. Elevating neuronal activity rapidly increased, while blocking activity decreased, a-synuclein release. In vivo microdialysis experiments in freely moving mice revealed that $\sim 70 \%$ of extracellular a-synuclein arises from neuronal activity-dependent pathway. Selective modulation of glutamatergic neurotransmission altered extracellular a-synuclein levels, implicating this specific neuronal network in the mechanism of activity-dependent release of a-synuclein. While neuronal activity tightly regulated a-synuclein release, elevated synaptic vesicle exocytosis per se was capable to elicit a-synuclein release. We also found that extracellular a-synuclein exists as high molecular weight species.
\end{abstract}

Conclusions: The present study uncovers a novel regulatory pathway associated with a-synuclein release, whose dysregulation might affect various pathological actions of extracellular a-synuclein including its trans-synaptic propagation.

Keywords: a-synuclein, Parkinson's disease, Propagation, Neuronal activity

\section{Background}

The pathological aggregation of $\alpha$-synuclein characterizes Parkinson's disease, dementia with Lewy bodies and multiple system atrophy collectively referred to as $\alpha$-synucleinopathies $[1,2]$. While $\alpha$-synuclein aggregates intracellularly, accumulating evidence suggests that extracellular $\alpha$-synuclein also has pathological significance [3]: studies have demonstrated that aggregated forms of extracellular $\alpha$-synuclein trigger trans-cellular spreading of $\alpha$-synuclein pathology [4-7]. Extracellular $\alpha$-synuclein oligomers impairs long-term potentiation (LTP), alters the glutamatergic synaptic transmission and $\alpha 3-\mathrm{Na}^{+} / \mathrm{K}^{+}$-ATPase activity $[8,9]$, and also activates inflammatory response in microglia [10]. Secreted monomeric $\alpha$-synuclein has been also shown to exhibit toxicity to cells [11], perturb calcium homeostasis [12] and induce fragmentation of lipid rafts [13].

$\alpha$-Synuclein is present in media of various cells overexpressing $\alpha$-synuclein and peripheral neurons $[6,11,14$, 15], brain interstitial fluid (ISF) [16] and also in cerebrospinal fluid $[17,18]$, suggesting that its release occurs independently of cell death. Now the phenomenon of $\alpha$ synculein release has been well documented, whereas the underlying mechanism that regulates $\alpha$-synuclein release has remained poorly investigated. To better understand the physiological release of $\alpha$-synuclein, we have examined the relationship between neuronal activity and $\alpha$-synuclein release both in cultured neurons and living mice.

\footnotetext{
* Correspondence: yamadaka@m.u-tokyo.ac.jp; iwatsubo@m.u-tokyo.ac.jp Department of Neuropathology, Graduate School of Medicine, The University of Tokyo, 7-3-1, Hongo, Bunkyo-ku, Tokyo 113-0033, Japan
}

(c) The Author(s). 2018 Open Access This article is distributed under the terms of the Creative Commons Attribution 4.0 International License (http://creativecommons.org/licenses/by/4.0/), which permits unrestricted use, distribution, and reproduction in any medium, provided you give appropriate credit to the original author(s) and the source, provide a link to the Creative Commons license, and indicate if changes were made. The Creative Commons Public Domain Dedication waiver (http://creativecommons.org/publicdomain/zero/1.0/) applies to the data made available in this article, unless otherwise stated. 


\section{Results}

Neuronal activity drives de novo release of a-synuclein from neurons

We hypothesized that neuronal activity regulates physiological release of $\alpha$-synuclein. Due to the artificial influences of over-expressed $\alpha$-synuclein on the secretory mechanism [19] as well as basal synaptic transmission $[20,21]$, we sought to measure release of endogenous $\alpha$-synuclein from cultured neurons.

Consistent with the hypothesis, we found that tetrodotoxin (TTX), a sodium channel blocker that inhibits the generation of action potential, significantly decreased $\alpha$-synuclein levels released in media (Fig. 1a).

The expression of $\alpha$-synuclein at the synapses of excitatory neurons $[22,23]$ led us to examine the involvement of excitatory neurotransmission. Thirty minutes exposure of glutamate increased extracellular $\alpha$-synuclein levels. Preincubation with a specific NMDA receptor antagonist, AP5, and an AMPA receptor antagonist, NBQX, abolished both basal and glutamate-evoked $\alpha$-synuclein release (Fig. 1b). The increase in $\alpha$-synuclein release by glutamate was not associated with changes in cellular $\alpha$-synuclein levels (Fig. 1c). While prolonged exposure of glutamate at higher dose $(2.5 \mathrm{~h}$ treatment of $100 \mu \mathrm{M}$ glutamate) increased the non-specific release of lactate dehydrogenase (LDH) in the media likely due to excitotoxicity, such increase was not observed in $30 \mathrm{~min}$ exposure of $20 \mu \mathrm{M}$ glutamate and other treatment groups (Fig. 1d). This demonstrates that neuronal activity influenced extracellular $\alpha$-synuclein levels by modulating the release, not by augmenting excitotoxicity or altering its expression level.

\section{Neuronal activity alters the steady-state levels of extracellular a-synuclein in vivo}

We reasoned if neuronal activity is a major regulator of $\alpha$-synuclein release, altering activity would also change its steady state levels in ISF. To test this in the context of intact neuronal network, we performed in vivo microdialysis that allows the measurement of real-time changes in ISF endogenous $\alpha$-synuclein on an hourly basis in freely moving mice. Following the collection of basal $\alpha$-synuclein, picrotoxin (PTX), a $\mathrm{GABA}_{\mathrm{A}}$ receptor antagonist, was locally and continuously administered to hippocampus through the microdialysis probes with $1000 \mathrm{kDa}$ cut-off membranes by reverse microdialysis to stimulate neurons. PTX significantly enhanced ISF $\alpha$-synuclein levels (Fig. 2a, b) in a dose dependent manner, suggesting that the degree of neuronal

\section{a}

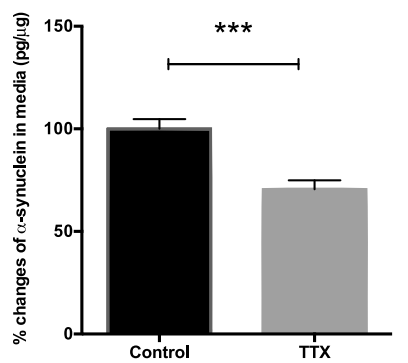

C

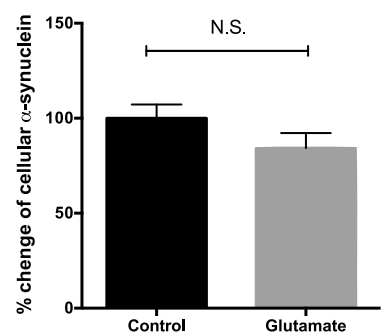

b

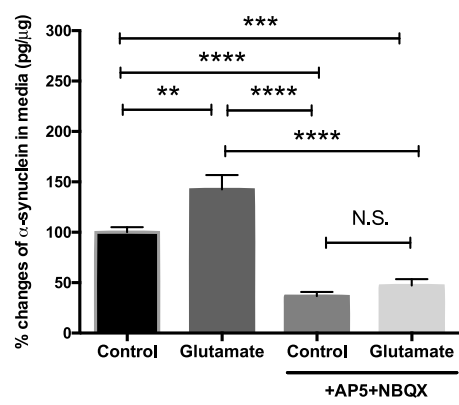

d

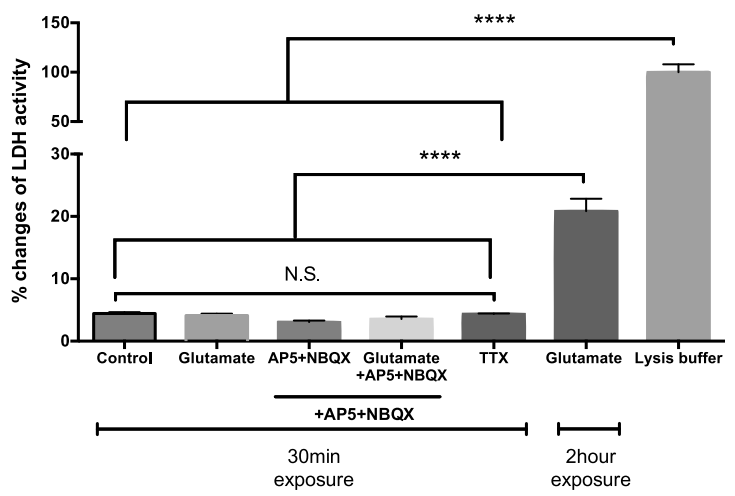

Fig. 1 Modulating neuronal activity alters a-synuclein release from neurons. a $\Pi \mathrm{TX}(1 \mu \mathrm{M}, 30 \mathrm{~min})$ decreased a-synuclein in the media. $N=12-16$. b Glutamate $(10 \mu \mathrm{M}, 30 \mathrm{~min})$ increased a-synuclein in the media, which was blocked by $50 \mu \mathrm{M}$ AP5 and $10 \mu \mathrm{M}$ NBQX. $N=8-20$. c Cellular asynuclein levels were not altered by glutamate. $N=8$. $\mathbf{d} \mathrm{LDH}$ activities in the media after indicated pharmacological treatments. $N=8-28 . \mathrm{mean}$ \pm SEM, ${ }^{* *} p<0.01,{ }^{* * *} p<0.001,{ }^{* * * *} p<0.0001$ using unpaired t test $(\mathbf{a}, \mathbf{c})$ or one-way ANOVA $(\mathbf{b}, \mathbf{d})$ 


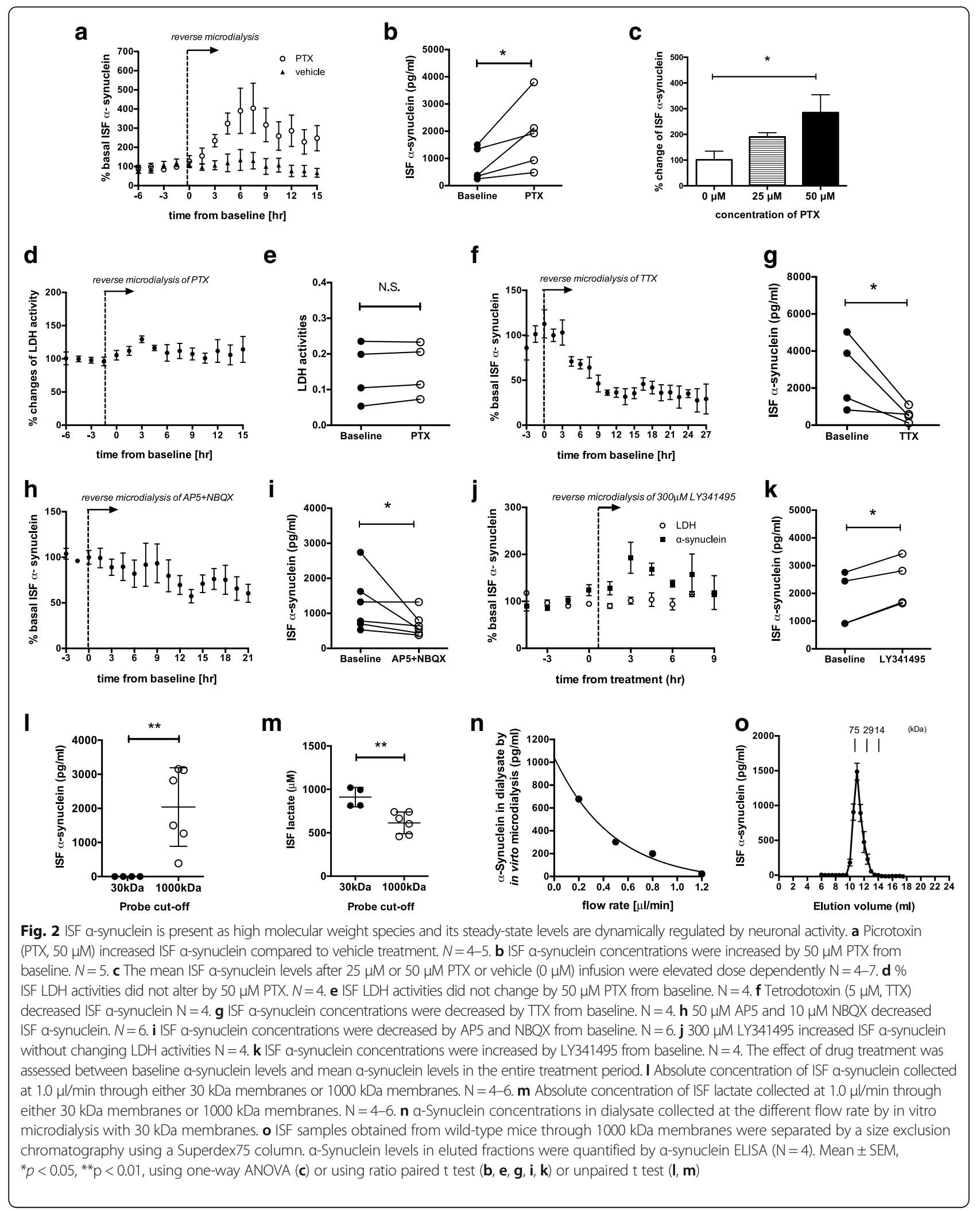


activation determines its levels (Fig. 2c). Consistent with the report that low dose of PTX only produces occasional spikes and does not cause any excitotoxicity [24], PTX did not increase ISF LDH activities (Fig. 2d, e), while the same dose significantly elevated ISF $\alpha$-synuclein levels.

In contrast to PTX, inhibiting neuronal activity by TTX significantly decreased ISF $\alpha$-synuclein levels by a maximum of $\sim 70 \%$ (Fig. 2f, g). TTX reduced ISF $\alpha$-synuclein not only in hippocampus but also in striatum (data not shown). This striking reduction in ISF $\alpha$-synuclein levels suggests that the majority of extracellular $\alpha$-synuclein arises from neuronal activity-dependent mechanisms.

Blocking glutamate receptors by AP5 and NBQX also significantly decreased ISF $\alpha$-synuclein levels (Fig. 2h, i). Metabotropic glutamate receptors $2 / 3$ negatively regulate glutamate release at the pre-synaptic terminal [24]. Thus, its inhibition enhances glutamate release. Infusion of a highly specific metabotropic receptor $2 / 3$ antagonist, LY341495 slightly but significantly elevated ISF $\alpha$-synuclein levels without changing LDH activities (Fig. 2j, k).

In order to examine the molecular weight size of ISF $\alpha$ synuclein, we performed in vivo microdialysis using probes with $30 \mathrm{kDa}$ cut-off membrane, which will predominantly collect monomeric $\alpha$-synuclein $(\sim 14 \mathrm{kDa})$ and possibly a dimeric form $(\sim 28 \mathrm{kDa})$. Surprisingly, $\alpha-$ synculein was not detected in ISF collected through $30 \mathrm{kDa}$ membranes although ISF lactate levels were not decreased with $30 \mathrm{kDa}$ compared to $1000 \mathrm{kDa}$ membranes (Fig. 2l, m). Recombinant $\alpha$-synuclein was detectable by in vitro microdialysis with $30 \mathrm{kDa}$ membranes in a flow ratedependent manner as indicated by an inverse relationship between concentration and flow rate [25], suggesting that at least monomeric $\alpha$-synuclein can pass through $30 \mathrm{kDa}$ membranes (Fig. 2n). To further verify whether ISF $\alpha-$ synculein exists in a form larger than $30 \mathrm{kDa}$, we separated ISF samples collected through $1000 \mathrm{kDa}$ cut-off membranes by a size-exclusion chromatography and measured the $\alpha$-synuclein levels in individual fractions. ISF $\alpha-$ synuclein was eluted as a single sharp peak with an apparent molecular weight of $60 \mathrm{kDa}$ (Fig. 2o). Although it is uncertain whether this represents $\alpha$-synuclein oligomer or $\alpha$-synuclein monomer bound to other proteins, it suggests that $\alpha$-synuclein forms a high molecular weight complex in ISF.

\section{Synaptic vesicle exocytosis per se is sufficient to enhance a-synuclein release}

Collectively, the results suggest that neuronal activity is one mechanism regulating $\alpha$-synuclein release. Glutamate activates post-synaptic receptors, depolarizes neurons and increases synaptic vesicle exocytosis. To further define which cellular process is associated with $\alpha$-synuclein release, we performed pharmacological experiments in neurons.
$\alpha$-Latrotoxin ( $\alpha$ LTX) binds to neurexin receptors on the presynaptic terminals and enhanced synaptic vesicles release through calcium influx independently of pre-synaptic depolarization [26, 27] (Fig. 3a). $\alpha$ LTX increased $\alpha$-synuclein release, which was blocked in the presence of EGTA (Fig. 3b). Next, to separately assess the effects of synaptic vesicle exocytosis and neuronal activity on $\alpha$-synuclein release, we treated neurons with $\alpha$ LTX in the presence of TTX, AP5 and NBQX to enhance synaptic vesicle release while simultaneously blocking depolarization and post-synaptic glutamate receptor activation. The inhibitor mixture containing TTX, AP5 and NBQX in the absence of $\alpha$ LTX significantly decreased $\alpha$-synuclein release. Interestingly, $\alpha$ LTX still enhanced $\alpha$-synuclein release in the presence of the inhibitor mixture (Fig. 3c), with no changes in LDH activities and cellular $\alpha$-synuclein levels (Fig. 3d, e). This suggests that pre-synaptic vesicle exocytosis is a critical downstream event associated with $\alpha$-synuclein release and post-synaptic receptor activation is not the prerequisite.

\section{Discussion}

Prior studies overexpressing $\alpha$-synuclein have reported multiple pathways that influence $\alpha$-synuclein release such as proteasomal stress, lysosomal dysfunction, mitochondrial dysfunction $[14,28]$, and sulfonylurea receptor 1 mediated mechanism [23]. While the studies have shown that cells under external stress release more $\alpha$ synuclein, the intrinsic mechanism that mediates endogenous $\alpha$-synuclein release from healthy neurons in brain have not been empirically investigated to date. In the present study, using several mechanistically distinct methods to modulate neuronal activity, we provided substantial evidence that de novo release of endogenous $\alpha$-synuclein highly depends on neuronal activity. More importantly, by measuring its real-time changes in freely moving wild-type mice, we also demonstrated that neuronal activity impacts the steady-state levels of extracellular $\alpha$-synuclein in vivo.

Previous studies have suggested that secreted soluble $\alpha$-synuclein exerts multiple effects. Intriguingly, many of its reported actions are associated with perturbation in neuronal/synaptic function at various levels, such as partitioning of voltage-gated calcium channels [29] or impairment in LTP [8] or alteration in synaptic activity [12] or increase in the susceptibility to depolarization by interacting with $\alpha 3-\mathrm{Na}^{+} / \mathrm{K}^{+}$-ATPase [9]. Thus, activity-dependent release of $\alpha$-synuclein may participate in a dynamic feedback mechanism on neuronal/synaptic function.

Extracellular $\alpha$-synuclein levels appear to highly rely on intrinsic neuronal activity compared to other secretory proteins released via an activity-dependent manner. For example, TTX only suppressed ISF A $\beta$ 


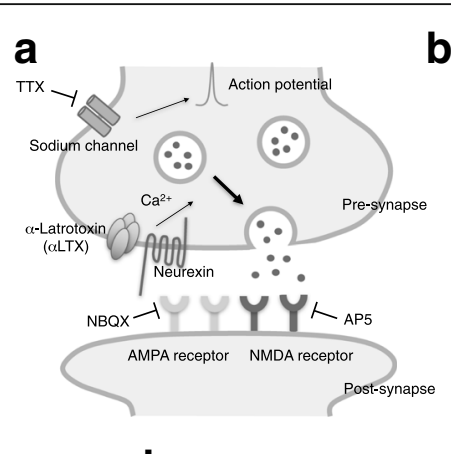

d

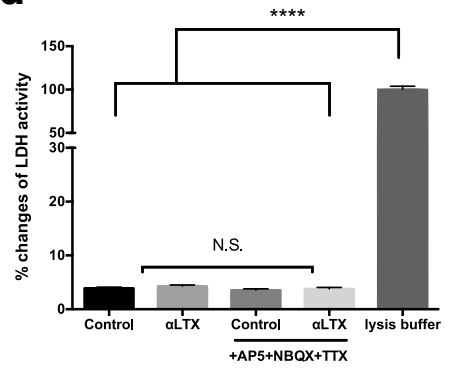

b

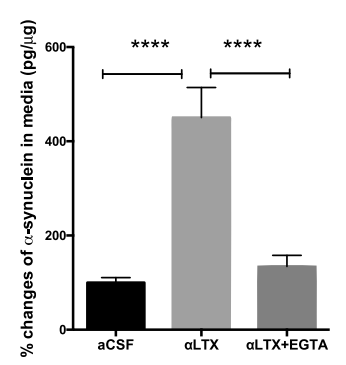

e
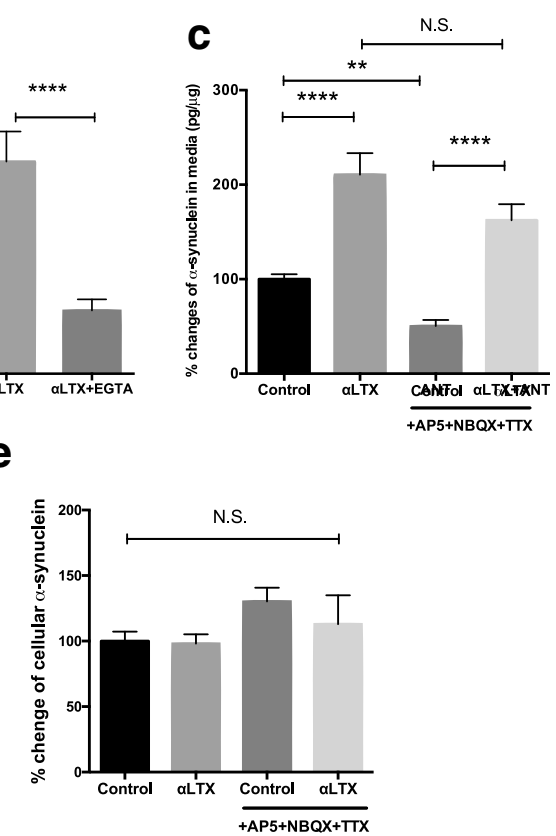

Fig. 3 Synaptic vesicle exocytosis is associated with a-synuclein release. a Schematic illustration of target molecules for the compounds used in the experiment. $\mathbf{b}$ a-Latrotoxin (aLTX, $0.5 \mathrm{nM}$ ) increased a-synuclein release, which was blocked by $4 \mathrm{mM} E G T A . N=8$. c aLTX significantly increased a-synuclein release in the presence or absence of $1 \mu \mathrm{M}$ TTX, $50 \mu \mathrm{M}$ AP5 and $10 \mu \mathrm{M}$ NBQX. N=16-32. $\mathbf{d} \mathrm{LDH}$ activities in the media were not altered by indicated pharmacological treatments. $N=16-24$. e Cellular a-synuclein levels were not altered by indicate pharmacological treatments. $\mathrm{N}=8$. mean $\pm \mathrm{SEM},{ }^{* *} p<0.001,{ }^{* * * *} p<0.0001$ using one-way ANOVA

levels by $\sim 30 \%$ despite its complete inhibition of action potentials, suggesting that remaining $\sim 70 \%$ pool of $\mathrm{A} \beta$ release arises from activity-independent mechanisms [27].

The steady-state levels of extracellular $\alpha$-synuclein are maintained based on the balance between release and clearance. The rapid decrease in ISF $\alpha$-synuclein by TTX also unveils that $\alpha$-synuclein is normally cleared rapidly from ISF. Such clearance might be mediated by extracellular protease such as neurosin, which has been shown to degrade $\alpha$-synuclein in culture media [30]. This is in sharp contrast to tau protein, which has a longer half-life in ISF, despite the common regulatory mechanism of release in an activity dependent manner [24, 31].

Our data suggests the link between synaptic activity and $\alpha$ synuclein release; nonetheless this is not necessarily equated to its release via synaptic vesicles. Alternatively, it is certainly possible that synaptic activity drives other associated secretory process directly responsible for $\alpha$-synuclein release.

$\alpha$-Synuclein release has been shown to occur via an exosome-mediated pathway $[5,11]$. Although detection of $\alpha$-synuclein directly by ELISA in this study suggested the presence of $\alpha$-synuclein not embedded in extracellular vesicles, it is unknown whether exosome-mediated release also occurs. Currently, the molecular mechanisms for exosome-independent $\alpha$-synuclein release remains largely unknown and should be explored in the future studies.
Although the current study focuses on the physiological release of $\alpha$-synuclein, it should further be investigated whether activity-dependent release promotes transmission of $\alpha$-synuclein pathology. Although it is uncertain that $\alpha$ synuclein forms oligomers in ISF, our study suggests that extracellular $\alpha$-synuclein exists as a high molecular weight complex. Given that $\alpha$-synuclein is capable of oligomerizing in the extracellular space [6], it is tempting to speculate that when local concentration of extracellular $\alpha$-synuclein at synapses is abnormally elevated by neuronal activation, it may culminate in the chronic accumulation of oligomeric $\alpha$ synuclein, which could ultimately facilitate the trans-synaptic spreading of $\alpha$-synuclein pathology. Similar concept has been proposed for the cell-to-cell propagation of tau pathology [32]. From this perspective, the present microdialysis technique with $1000-\mathrm{kDa}$ cut-off membranes might serve as a valuable tool to measure extracellular pathogenic $\alpha$ synuclein and directly test the efficacy of potential pharmacological treatments in vivo.

\section{Conclusions}

We have demonstrated that neuronal/synaptic activity regulates $\alpha$-synuclein release in vivo. Trans-synaptic spreading of pathology through neuronal network has been only reported in a certain class of pathogenic cytoplasmic proteins such as $\alpha$-synuclein and tau. Of note, tau release is also dynamically regulated by 
synaptic activity [24, 33]. Our findings on the activitydependent release of $\alpha$-synuclein may underscore the common mechanistic link between trans-synaptic propagation and the synaptic activities in different types of neurodegenerative disorders.

\section{Methods}

\section{Compounds}

$\alpha$-Latrotoxin and TTX were purchased from Alamone Labs and Wako Pure Chemical Industries respectively. Glutamate and picrotoxin were purchased from SigmaAldrich. D-AP5, NBQX and LY341495 were purchased from Abcam.

\section{Culture of mouse primary neurons and measurements of} a-synculein release from primary neurons

Primary cortical neurons were prepared from embryonic day $14 \mathrm{C} 57 \mathrm{~B} 6 / \mathrm{J}$ mouse embryos and plated on dishes coated with poly-D-lysine. Neurons were maintained in Neurobasal medium (Life technologies) containing 1\% Glutamax I (Life technologies), 2\% B-27 supplement (Life technologies), penicillin, streptomycin and cytosine arabinofuranoside to restrict proliferation of non-neuronal cells. Neurons cultured 14 days in vitro were rinsed once with DPBS and then incubated with Neurobasal phenol red minus medium or artificial CSF (aCSF; $1.3 \mathrm{mM} \mathrm{CaCl}_{2}$, $1.2 \mathrm{mM} \mathrm{MgSO}_{4}, 3 \mathrm{mM} \mathrm{KCl}, 0.4 \mathrm{mM} \mathrm{KH}_{2} \mathrm{PO}_{4}, 25 \mathrm{mM} \mathrm{Na}$ $\mathrm{HCO}_{3}$, and $122 \mathrm{mM} \mathrm{NaCl}$, pH 7.4) containing 1\% Gluta$\max$ I, $2 \%$ B-27 supplement with or without indicated chemicals for $30 \mathrm{~min}$ at $37{ }^{\circ} \mathrm{C}$ (treatment period). To maximize the inhibitory effects of TTX, AP5 and NBQX on the neuronal activity, these inhibitors were added both in treatment period and pre-incubation period (for $2 \mathrm{~h}$ at $\left.37{ }^{\circ} \mathrm{C}\right)$. At the end of the experiments, collected media was centrifuged to remove cell debris and the supernatant was used for the further analysis. Neurons were lysed with RIPA (150 mM NaCl, $50 \mathrm{mM}$ Tris, $0.5 \%$ deoxycholic acid, 1\% Triton X-100, and 0.5\% SDS, 25 mM EDTA, pH 8.0) supplemented with Complete (Roche) and PhosSTOP (Roche). $\alpha$-Synuclein levels were normalized by cellular protein levels determined with BCA assay. To minimize inter-experiment variations, $\alpha$-synuclein levels/total protein were further normalized by untreated control samples in the same experiment.

\section{In vivo microdialysis}

In vivo microdialysis using $1000 \mathrm{kDa}$ cut-off Atmos microdialysis probes (Eicom microdialysis) was performed with slight modifications from the previously described method [24, 25]. A guide cannula was stereotaxically implanted in the hippocampus (bregma $-3.1 \mathrm{~mm}, 2.5 \mathrm{~mm}$ lateral to midline, $1.2 \mathrm{~mm}$ below dura at a $12.5^{\circ}$ angle) or the striatum (bregma $+0.5 \mathrm{~mm}, 1.8 \mathrm{~mm}$ lateral to midline, $1.4 \mathrm{~mm}$ below dura at a $0^{\circ}$ angle) under anesthesia and cemented. A Syringe pump (KDS-101, KD scientific) and a roller pump (ERP-10, Eicom microdialysis) were operated simultaneously for a push-pull microdialysis [34]. As a perfusion buffer, 4\% BSA solution in aCSF was made fresh on the day and filtered through a $0.1 \mu \mathrm{m}$ membrane. The probe was inserted through a guide cannula and perfused at $10 \mu \mathrm{l} / \mathrm{min}$ for $1 \mathrm{~h}$ and then ISF was collected at $1.0 \mu \mathrm{l} / \mathrm{min}$ by refrigerated fraction collectors (Univentor 820 microsampler, Univentor). Microdialysis with $30 \mathrm{kDa}$ cut-off membranes (BR-2 probes, BASi) was operated only by a syringe pump. To ensure the stable collection of $\alpha$-synuclein, the first $9 \mathrm{~h}$ fractions were excluded from analysis. The inclusion of chemicals in the perfusion buffer allows them to diffuse out to ISF. This technique is called reverse microdialysis. Reverse microdialysis was performed in hippocampus unless specifically mentioned. To infuse chemicals via reverse microdialysis, a normal perfusion buffer was switched to a perfusion buffer containing various chemicals. As a vehicle control for picrotoxin, a perfusion buffer containing $0.05 \%$ DMSO was administered. To assess the maximal effect of TTX or AP5 + NBQX, the mean $\alpha$-synuclein or LDH levels during the final $3 \mathrm{~h}$ of treatment were compared.

\section{In vitro microdialysis}

In vitro microdialysis with $30 \mathrm{kDa}$ cut-off membranes (BR-2 probes, BASi) was also operated by a syringe pump. Recombinant $\alpha$-synuclein from SensoLyte $\alpha$ synuclein ELISA kit (Anaspec) was dissolved in aCSF at $1 \mu \mathrm{g} / \mathrm{ml}$ and prepared in an Axygen maximum recovery tube. During microdialysis, flow rate varied from $0.2-$ $1.2 \mu \mathrm{l} / \mathrm{min}$ and $\alpha$-synuclein concentration in each flow rate was determined by $\alpha$-synuclein ELISA.

\section{Size exclusion chromatography}

ISF samples were pooled and separated by a size exclusion chromatography using Superdex 75 column (GE healthcare). PBS was run at $0.5 \mathrm{ml} / \mathrm{min}$ with an AKTA explorer 10S (GE healthcare). $\alpha$-Synuclein levels in each fraction were determined $\alpha$-synuclein ELISA. LMW calibration kit to determine molecular weights was purchased from GE healthcare.

\section{a-Synuclein ELISA}

$\alpha$-Synuclein levels in media or dialysates were determined at the end of collection by SensoLyte $\alpha$-synuclein ELISA kit (Anaspec).

\section{Lactate assay}

Lactate levels in ISF were determined by lactate assay kit (Biovision).

\section{LDH assay}

LDH activities were measured by cytotoxicity detection kit (Roche). A reference absorbance at $600 \mathrm{~nm}\left(\mathrm{~A}_{600}\right)$ 
was measured and subtracted from absorbance at $490 \mathrm{~nm}\left(\mathrm{~A}_{490}\right)$. Maximum $\mathrm{LDH}$ release (100\%) was induced by adding 5\% lysis buffer from a cytotoxicity detection kit to media and \% cell toxicity was calculated.

\section{Statistical analysis}

All statistical analysis was performed using Prism 6 (Graph Pad software). The comparison between baseline and treatment was done by two-tailed ratio paired $t$ test. The comparison of two groups and multiple groups were done by two-tailed unpaired $t$ test and one-way ANOVA with Tukey's post-hoc test respectively.

\section{Animals}

All animal studies were reviewed and approved by the Institutional Animal Care and Use Committee of the Graduate School of Medicine at the University of Tokyo. 2-6 month old wild type male mice on C57B6/J background were purchased from Japan SLC (Hamamatsu, Shizuoka, Japan).

\section{Abbreviations}

GAPDH: Glyceraldehyde 3-phosphate dehydrogenase; ISF: Brain interstitial fluid; LDH: Lactate dehydrogenase; PTX: Picrotoxin; TTX: Tetrodotoxin; aLTX: a-latrotoxin

\section{Acknowledgements}

We thank all members in Iwatsubo's lab for helpful suggestions and discussion.

\section{Funding}

This work was supported by JSPS KAKENHI, Grant-in-Aid for Research Activity Start-up (K.Y.)(Grant number: 26890009) and Grant-in-Aid for Young Scientists (B) (K.Y.)(Grant number: 16 K20969). This research is partially supported by the program for Brain Mapping by Integrated Neurotechnologies for Disease Studies (Brain/MINDS) from Japan Agency for Medical Research and development, AMED (T.I.) (JP17dm0207014h0004).

\section{Availability of data and materials}

The datasets supporting the conclusions of this article are included within the article.

\section{Authors' contributions}

KY conceived, designed the experiments and performed all experiments. $\mathrm{KY}$ and $\mathrm{TI}$ wrote the manuscript. Both authors read and approved the final manuscript.

\section{Ethics approval}

All animal studies were reviewed and approved by the Institutional Animal Care and Use Committee of the Graduate School of Medicine at the University of Tokyo.

\section{Consent for publication}

Not applicable.

\section{Competing interests}

The authors declare that they have no competing interests.

\section{Publisher's Note}

Springer Nature remains neutral with regard to jurisdictional claims in published maps and institutional affiliations.
Received: 23 October 2017 Accepted: 6 February 2018

Published online: 22 February 2018

\section{References}

1. Spillantini MG, Schmidt ML, Lee VM, Trojanowski JQ, Jakes R, Goedert M. Alpha-synuclein in Lewy bodies. Nature. 1997;388:839-40.

2. Horowitz NH, Bonner D, Mitchell HK, Tatum EL, Beadle GW. Genic control of biochemical reactions in Neurospora. Am Nat. 1945;79:304-17.

3. Lee HJ, Bae EJ, Lee SJ. Extracellular a-synuclein-a novel and crucial factor in Lewy body diseases. Nat Rev Neurol. 2014;10:92-8.

4. Volpicelli-Daley LA, Luk KC, Lee VM-Y. Addition of exogenous a-synuclein preformed fibrils to primary neuronal cultures to seed recruitment of endogenous a-synuclein to Lewy body and Lewy neurite-like aggregates. Nat Protoc. 2014;9:2135-46.

5. Danzer KM, Kranich LR, Ruf WP, Cagsal-Getkin O, Winslow AR, Zhu L, Vanderburg CR, McLean PJ. Exosomal cell-to-cell transmission of alpha synuclein oligomers. Mol Neurodegener. 2012;7:42.

6. Danzer KM, Ruf WP, Putcha P, Joyner D, Hashimoto T, Glabe C, Hyman BT, McLean PJ. Heat-shock protein 70 modulates toxic extracellular a-synuclein oligomers and rescues trans-synaptic toxicity. FASEB J. 2011;25:326-36.

7. Luk KC, Kehm V, Carroll J, Zhang B, O'Brien P, Trojanowski JQ, Lee VM. Pathological a-synuclein transmission initiates Parkinson-like neurodegeneration in nontransgenic mice. Science. 2012;338:949-53.

8. Diógenes MJ, Dias RB, Rombo DM, Miranda HV, Maiolino F, Guerreiro P, Näsström T, Franquelim HG, Oliveira LMA, Castanho MARB, Lannfelt L, Bergström J, Ingelsson M, Quintas A, Sebastião AM, Lopes LV, Outeiro TF. Extracellular alpha-Synuclein oligomers modulate synaptic transmission and impair LTP via NMDA-receptor activation. J Neurosci. 2012;32:11750-62.

9. Shrivastava AN, Redeker V, Fritz N, Pieri L, Almeida LG, Spolidoro M, Liebmann T, Bousset L, Renner M, Léna C, Aperia A, Melki R, Triller A. a-synuclein assemblies sequester neuronal a3-Na+/K+-ATPase and impair $\mathrm{Na}+$ gradient. EMBO J. 2015;34:2408-23.

10. Kim C, Ho D-H, Suk J-E, You S, Michael S, Kang J, Joong Lee S, Masliah E, Hwang D, Lee H-J, Lee S-J. Neuron-released oligomeric a-synuclein is an endogenous agonist of TLR2 for paracrine activation of microglia. Nat Commun. 2013:4:1562

11. Emmanouilidou E, Melachroinou K, Roumeliotis T, Garbis SD, Ntzouni M Margaritis LH, Stefanis L, Vekrellis K. Cell-produced alpha-synuclein is secreted in a calcium-dependent manner by exosomes and impacts neuronal survival. J Neurosci. 2010;30:6838-51.

12. Melachroinou K, Xilouri M, Emmanouilidou E, Masgrau R, Papazafiri P, Stefanis $L$, Vekrellis K. Deregulation of calcium homeostasis mediates secreted a-synuclein-induced neurotoxicity. Neurobiol Aging. 2013; 34:2853-65.

13. Emanuele M, Esposito A, Camerini S, Antonucci F, Ferrara S, Seghezza S, Catelani T, Crescenzi M, Marotta R, Canale C, Matteoli M, Menna E, Chieregatti E. Exogenous alpha-Synuclein alters pre- and post-synaptic activity by fragmenting lipid rafts. EBioMedicine. 2016;7:191-204.

14. Lee $\mathrm{H}-\mathrm{J}$, Patel $\mathrm{S}$, Lee $\mathrm{S}$-J. Intravesicular localization and exocytosis of alpha-synuclein and its aggregates. J Neurosci. 2005;25:6016-24.

15. Paillusson S, Clairembault T, Biraud M, Neunlist M, Derkinderen P. Activitydependent secretion of alpha-synuclein by enteric neurons. J Neurochem. 2013;125:512-7

16. Emmanouilidou E, Elenis D, Papasilekas T, Stranjalis G, Gerozissis K, loannou $P C$, Vekrellis K. Assessment of a-synuclein secretion in mouse and human brain parenchyma. PLoS One. 2011:6:1-9.

17. Kang JH, Irwin DJ, Chen-Plotkin AS, Siderowf A, Caspell C, Coffey CS, Waligórska T, Taylor P, Pan S, Frasier M, Marek K, Kieburtz K, Jennings D, Simuni T, Tanner CM, Singleton A, Toga AW, Chowdhury S, Mollenhauer B, Trojanowski JQ, Shaw LM. Association of cerebrospinal fluid $\beta$-amyloid 1-42, t-tau, p-tau <inf > 181</inf>, and a-synuclein levels with clinical features of drug-naive patients with early parkinson disease. JAMA Neurol. 2013;70: 1277-87.

18. Mollenhauer B, Locascio JJ, Schulz-Schaeffer W, Sixel-Döring F, Trenkwalder C, Schlossmacher MG. a-Synuclein and tau concentrations in cerebrospinal fluid of patients presenting with parkinsonism: a cohort study. Lancet Neurol. 2011;10:230-40.

19. Simón D, García-García E, Gómez-Ramos A, Falcón-Pérez JM, Díaz-Hernández M, Hernández F, Avila J. Tau overexpression results in its secretion via membrane vesicles. Neurodegener Dis. 2012;10:73-5. 
20. Wu N, Joshi PR, Cepeda C, Masliah E, Levine MS. Alpha-Synuclein overexpression in mice alters synaptic communication in the corticostriatal pathway. J Neurosci Res. 2010;88:1764-76.

21. Lundblad M, Decressac M, Mattsson B, Björklund A. Impaired neurotransmission caused by overexpression of a-synuclein in nigral dopamine neurons. Proc Natl Acad Sci U S A. 2012;109:3213-9.

22. Taguchi K, Watanabe Y, Tsujimura A, Tatebe H, Miyata S, Tokuda T, Mizuno T, Tanaka M. Differential expression of alpha-synuclein in hippocampal neurons. PLoS One. 2014:9:e89327.

23. Emmanouilidou E, Minakaki G, Keramioti MV, Xylaki M, Balafas E, Chrysanthou-Piterou M, Kloukina I, Vekrellis K. GABA transmission via ATP-dependent $\mathrm{K}+$ channels regulates a-synuclein secretion in mouse striatum. Brain. 2016;139:871-90.

24. Yamada K, Holth JK, Liao F, Stewart FR, Mahan TE, Jiang H, Cirrito JR, Patel TK, Hochgräfe K, Mandelkow E-M, Holtzman DM. Neuronal activity regulates extracellular tau in vivo. J Exp Med. 2014;211:387-93.

25. Yamada K, Cirrito JR, Stewart FR, Jiang H, Finn MB, Holmes BB, Binder LI, Mandelkow E-M, Diamond MI, Lee VM-Y, Holtzman DM. In vivo microdialysis reveals age-dependent decrease of brain interstitial fluid tau levels in P301S human tau transgenic mice. J Neurosci. 2011;31:13110-7.

26. Südhof TC. Alpha-Latrotoxin and its receptors: neurexins and CIRL/ latrophilins. Annu Rev Neurosci. 2001;24:933-62.

27. Cirrito JR, Yamada KA, Finn MB, Sloviter RS, Bales KR, May PC, Schoepp DD, Paul SM, Mennerick S, Holtzman DM. Synaptic activity regulates interstitial fluid amyloid-beta levels in vivo. Neuron. 2005;48:913-22.

28. Jang A, Lee HJ, Suk JE, Jung JW, Kim KP, Lee SJ. Non-classical exocytosis of a-synuclein is sensitive to folding states and promoted under stress conditions. J Neurochem. 2010;113:1263-74.

29. Ronzitti G, Bucci G, Emanuele M, Leo D, Sotnikova TD, Mus LV, Soubrane $\mathrm{CH}$, Dallas ML, Thalhammer A, Cingolani LA, Mochida S, Gainetdinov RR, Stephens GJ, Chieregatti E. Exogenous a-Synuclein decreases raft partitioning of Cav2.2 channels inducing dopamine release. J Neurosci. 2014:34:10603-15.

30. Tatebe H, Watanabe Y, Kasai T, Mizuno T, Nakagawa M, Tanaka M, Tokuda T. Extracellular neurosin degrades a-synuclein in cultured cells. Neurosci Res. 2010;67:341-6.

31. Yamada K, Patel TK, Hochgräfe K, Mahan TE, Jiang H, Stewart FR, Mandelkow E-M, Holtzman DM. Analysis of in vivo turnover of tau in a mouse model of tauopathy. Mol Neurodegener. 2015;10:55

32. Wu JW, Hussaini SA, Bastille IM, Rodriguez GA, Mrejeru A, Rilett K, Sanders DW, Cook C, Fu H, Boonen RACM, Herman M, Nahmani E, Emrani S, Figueroa YH, Diamond MI, Clelland CL, Wray S, Duff KE. Neuronal activity enhances tau propagation and tau pathology in vivo. Nat Neurosci. 2016:19:1085-92.

33. Pooler AM, Phillips EC, Lau DHW, Noble W, Hanger DP. Physiological release of endogenous tau is stimulated by neuronal activity. EMBO Rep. 2013;14:389-94.

34. Yamada K. In vivo microdialysis of brain interstitial fluid for the determination of extracellular tau levels. Methods Mol Biol. 2017:1523:285-96.

\section{Submit your next manuscript to BioMed Central and we will help you at every step:}

- We accept pre-submission inquiries

- Our selector tool helps you to find the most relevant journal

- We provide round the clock customer support

- Convenient online submission

- Thorough peer review

- Inclusion in PubMed and all major indexing services

- Maximum visibility for your research

Submit your manuscript at www.biomedcentral.com/submit

) Biomed Central 